\title{
Falx cerebelli meningioma: Technical note
}

\author{
Amit Agrawal \\ Professor of Neurosurgery, Department of Neurosurgery, Narayana Medical College Hospital, \\ Chinthareddypalem, Nellore, Andhra Pradesh (India)
}

\begin{abstract}
The falx cerebelli is a small sickle-shaped fold of dura mater below the tentorium cerebelli, which projects forward into the posterior cerebellar notch. We report a rare case of 28 year female presented with the history of headache of six months duration off and it increased in severity and frequency over last 15 days. Imaging findings were suggestive of meningiona arising from the falx cerebelli. The lesion could be excised totally and safely.

Key words: Falx cerebelli, meningioma, posterior cranial fossa.

\section{Introduction}

The falx cerebelli is a small sickle-shaped fold of dura mater below the tentorium cerebelli, which projects forward into the posterior cerebellar notch. Normally, the falx cerebelli is between 2.8 and $4.5 \mathrm{~cm}$ in length and is approximately 1-2 mm thick and usually harbors a single occipital venous sinus at its posterior attachment. $(4,6)$ We report a rare case of meningiona arising from the falx cerebelli and review the relevant literature.
\end{abstract}

\section{Case Report}

A 28 year female presented with the history of headache of six months duration off and it increased in severity and frequency over last 15 days. She was also complaining of giddiness and swaying while walking. There was no history of blurring of vision, vomiting or loss of consciousness. Neurological examination revealed no deficits or physical symptoms. Computed tomography demonstrated a ill demarcated isodense mass, enhancing well after contrast administration with no calcification, in the cerebellar vallecula associated with obstructive hydrocephalus (Figures 1 and 2). MR imaging showed that the lesion was an extra-axial mass, appearing homogeneously isointense on T1-weighted images, and hyperintense on T2-weighted images, compared to the adjacent cerebellum (Figure 3). The preoperative diagnosis was posterior cranial fossa meningioma attached to the falx cerebelli. The lesion was exposed by median suboccipital craniectomy, the dura was opened in "Y" shaped manner. Occipital sinus was occluded by the tumor and there was no bleeding from the sinus. There was firm, grayish avascular mass attached to the falx cerebelli. The mass was initially completely detached from the falx. The arachnoid plane was well preserved. The dural attachment was also excised. Total en bloc resection could be 
performed with minimal blood loss. The histological diagnosis was meningioma of the cerebellar falx. The patient's postoperative course was unremarkable, follow up CT scan showed complete excision of the lesion and reduction in the size of the ventricles (Figures $4 a$ and $b$ ).

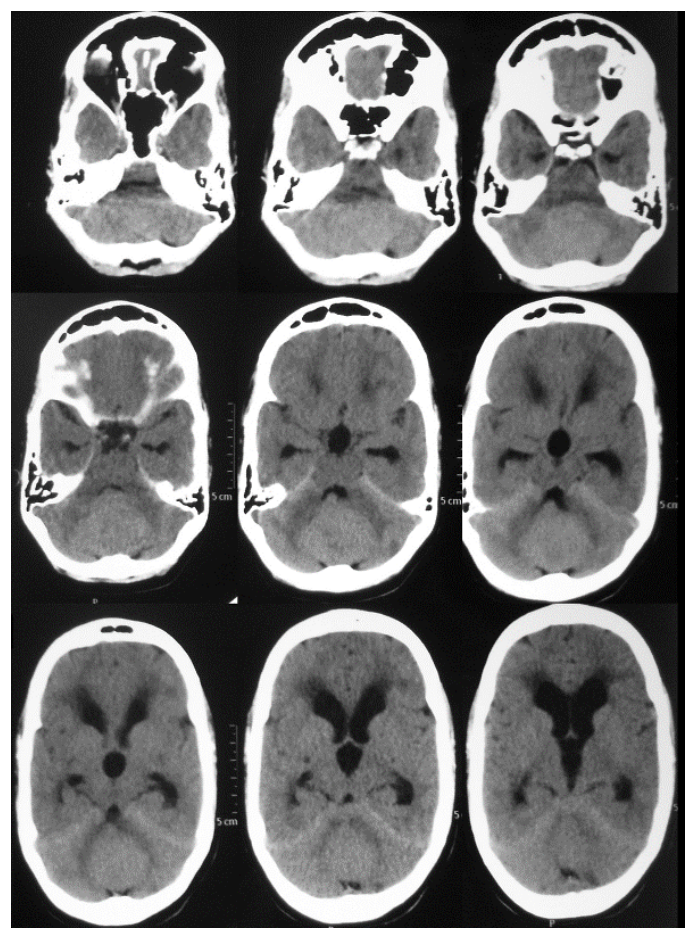

Figure 1 - CT scan brain plain study showing an isodense posterior fossa midline mass compressing the cerebellar vermis and fourth ventricle with obstructive hydrocephalus

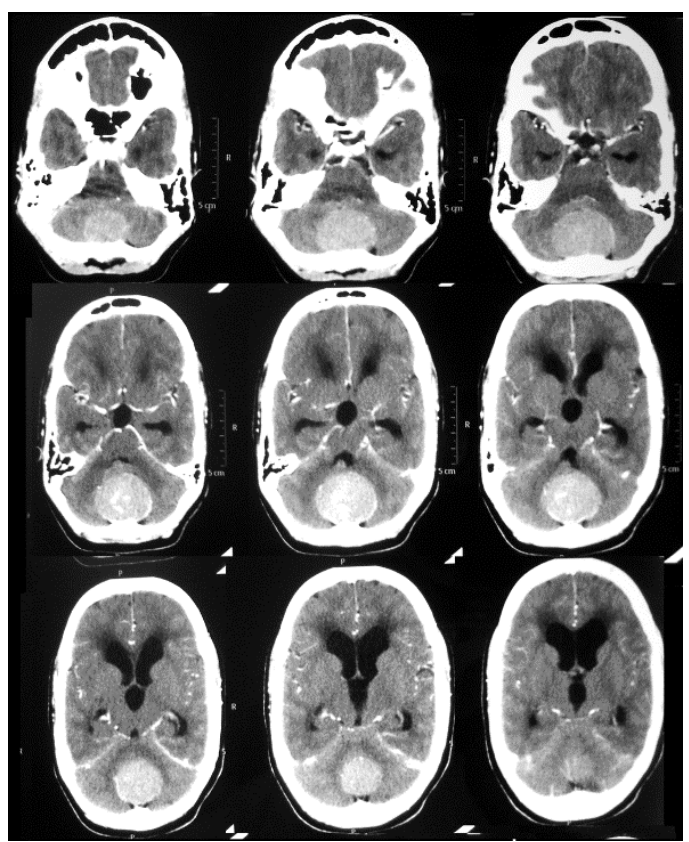

Figure 2 - The lesion was enhacing well after contrast administration

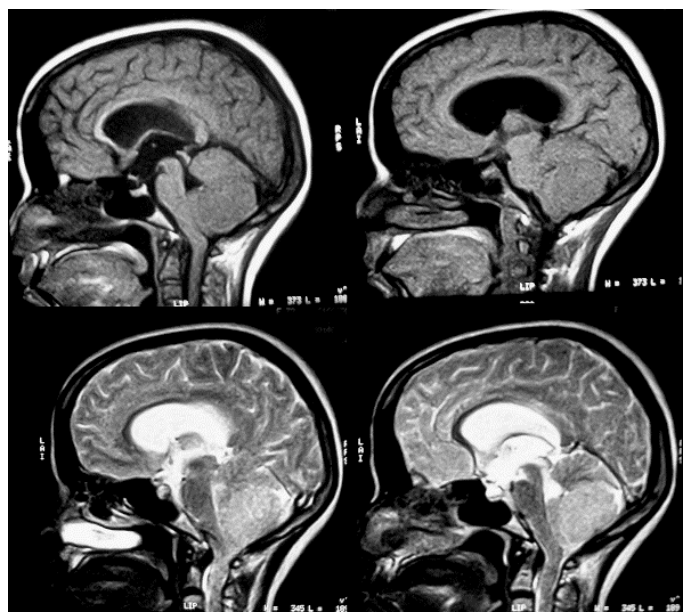

Figure 3 - MRI images sagittal T1-weighted image showing the homogeneously isointense lesion, the lesion was becoming hyperintense on T2-weighted images 
DOI: 10.2478/romneu-2014-0046
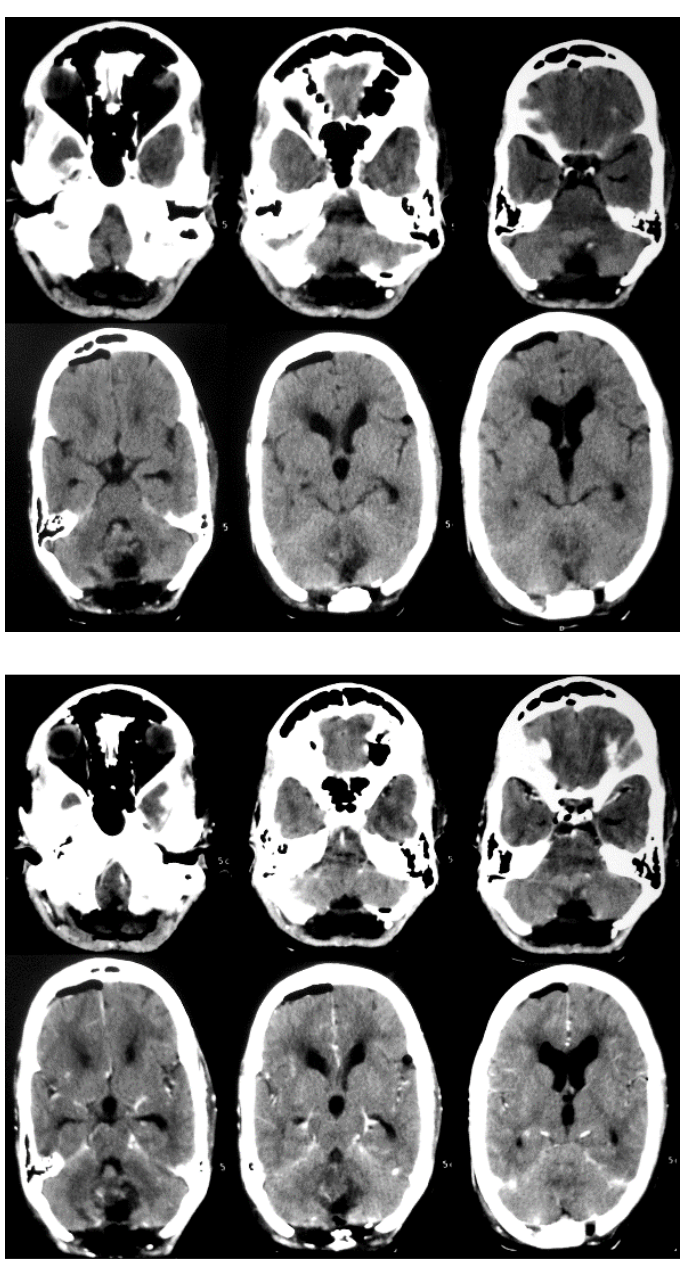

Figures $4 \mathbf{a}$ and $\mathbf{b}$ - CT brain plain and contrast showing complete excision

\section{Discussion}

Posterior cranial fossa meningiomas either involve cerebellar convexity or lateral tentorial meningiomas (8) and the incidences of tentorial and posterior fossa meningiomas have been described $5 \%$ and $10 \%$ of all intracranial meningiomas, respectively. (12) Lesions arising from the falx cerebelli are rarely described in the engllish literature and include meningioma and cavernous hemangioma. (5) On MR imaging the appearance of posterior cranial fossa meningioma can mimic other tumors i.e. that of cavernous hemangioma and based only on radiological investigations one cannot distinguish dural cavernous hemangioma from meningioma. (3, 9) For the supratentorial falcine meningiomas it has been described that "falcine meningioma frequently have a dumbbell shape and invaginate into the medial aspects of both left and right hemispheres and in some patients the tumor grows into the inferior edge of the sagittal sinus and can completely be concealed by the overlying cortex and that typically these lesions do not involve the superior sagittal sinus". $(1,2)$ The falx cerbelli lesion in present case had similar pattern of growth, however in contrary to the supratentorial parasagittal and falx meningiomas where these lesions are in the close vicinity of the venous vessels with crucial importance for the cerebral circulation that also make their surgical treatment is sometimes very challenging, (7) we found that it was easy to remove this tumor in present case. The tumor was excised based on the well know principles of meningioma surgery composed of four essential consecutive steps; devascularization, detachment, debulking, and dissection. (10) Apart from this as has been described a large median suboccipital craniotomy exposes well the falx cerebellar and also there is well preserved arachnoid plane that makes the total en bloc resection possible with minimal blood loss. (5) The occipital sinus did not pose a problem as it was closed and as has been described probably there would had been development of enough 
venous drainage because of gradual but complete obstruction of the normal venous drainage due to invasion of meningioma. (11, 13)

\author{
Correspondence \\ Dr. Amit Agrawal \\ Professor of Neurosurgery \\ Department of Neurosurgery \\ Narayana Medical College Hospital \\ Chinthareddypalem \\ Nellore-524003 \\ Andhra Pradesh (India) \\ Email-dramitagrawal@gmail.com \\ dramit_in@yahoo.com \\ Mobile- +91-8096410032
}

\section{References}

1.Chung SB, Kim CY, Park CK, Kim DG, Jung HW (2007) Falx meningiomas: surgical results and lessons learned from 68 cases. J Korean Neurosurg Soc 42:276-280

2.Cushing H (1962) Meningiomas: their classification, regional behaviour, life history, and surgical end results. Hafner Pub. Co. New York,

3.Goel A, Achwal S, Nagpal RD (1993) Dural cavernous haemangioma of posterior cranial fossa. J Postgrad Med 39:222-223
4.Gray H, Standring S, Ellis H, Berkovitz BKB (2005) Gray's anatomy : the anatomical basis of clinical practice. Elsevier Churchill Livingstone Edinburgh ; New York 5.Ito $M$, Kamiyama $H$, Nakamura $T$, Nakajima $H$, Tokugawa J (2009) Dural cavernous hemangioma of the cerebellar falx. Neurol Med Chir (Tokyo) 49:410-412

6.Lang J (1991) Clinical anatomy of the posterior cranial fossa and its foramina. G. Thieme Verlag ; Thieme Medical Publishers Stuttgart ; New York

7.Nowak A, Marchel A (2007) Surgical treatment of parasagittal and falx meningiomas. Neurol Neurochir Pol 41:306-314

8.Roberti F, Sekhar LN, Kalavakonda C, Wright DC (2001) Posterior fossa meningiomas: surgical experience in 161 cases. Surg Neurol 56:8-20; discussion 20-21

9.Sathi S, Folkerth R, Madsen JR (1992) Cavernous angioma of the posterior fossa dura mimicking a meningioma: case report and review of literature. Surg Neurol 38:257-260

10.Suga Y, Tsutsumi S, Higo T, Kondo A, Abe Y, Yasumoto Y, Ito M (2008) [Huge falx meningioma resected en bloc following acute brain swelling: a case report]. No Shinkei Geka 36:819-823

11.Suzuki S, Mizoi K, Kato S, Suzuki J (1988) [A successful removal of huge confluence meningioma]. No Shinkei Geka 16:289-294

12.Tamaki M, Tsuruoka S (1995) Unusual recurrence pattern in peritorcular meningioma--case report. Neurol Med Chir (Tokyo) 35:92-95

13.Tanaka Y, Sugita K, Kobayashi S, Hongo K (1985)

Straight sinus meningioma. Surg Neurol 24:550-554 